\title{
Decomposition Analysis of Void Reactivity Coefficient for Innovative and Modified BWR Assemblies
}

\author{
Andrius Slavickas, Raimondas Pabarčius, Aurimas Tonkūnas, and Gediminas Stankūnas \\ Lithuanian Energy Institute, Breslaujos Street 3, 44403 Kaunas, Lithuania \\ Correspondence should be addressed to Andrius Slavickas; andriussl@mail.lei.lt
}

Received 14 November 2013; Accepted 14 February 2014; Published 18 March 2014

Academic Editor: Arkady Serikov

Copyright (C) 2014 Andrius Slavickas et al. This is an open access article distributed under the Creative Commons Attribution License, which permits unrestricted use, distribution, and reproduction in any medium, provided the original work is properly cited.

\begin{abstract}
The decomposition analysis of void reactivity coefficient for innovative BWR assemblies is presented in this paper. The innovative assemblies were loaded with high enrichment $\mathrm{UO}_{2}$ and MOX fuels. Additionally the impact of the moderation enhancement on the void reactivity coefficient through a full fuel burnup discharge interval was investigated for the innovative assembly with MOX fuel. For the numerical analysis the TRITON functional module of SCALE code with ENDF/B-VI cross section library was applied. The obtained results indicate the influence of the most important isotopes to the void reactivity behaviour over a fuel burnup interval of $70 \mathrm{GWd} / \mathrm{t}$ for both $\mathrm{UO}_{2}$ and MOX fuels. From the neutronic safety concern positive void reactivity coefficient values are observed for MOX fuel at the beginning of the fuel irradiation cycle. For extra-moderated assembly designs, implementing 8 and 12 water holes, the neutron spectrum softening is achieved and consequently the lower void reactivity values. Variations in void reactivity coefficient values are explained by fulfilled decomposition analysis based on neutrons absorption reactions for separate isotopes.
\end{abstract}

\section{Introduction}

The two-phase flow regime is a standard for BWR reactor core. By increasing the reactor power and reaching the boiling point, the formed steam displaces the moderator in the coolant channels within the core. These displacements reduce the moderator-to-fuel ratio and result in the significant reactivity changes. Therefore a void reactivity coefficient, which defines a change of the multiplication factor of the system $\left(k_{\text {eff }}\right)$ caused by variations in the fuel cross sections from the moderator density changes. Void reactivity coefficient values vary for different fuel designs and fuel isotopic compositions, thus the understanding of coefficient values variations nature is one of prime importance for BWR reactors safety assessment. The objective of this paper is not to justify the analyzed fuel assemblies' designs for the safe operation (task for the designers) but to provide better understanding and to highlight the main contributors to void reactivity coefficient changes during the fuel burnup for different fuel assemblies' designs.

The plutonium recycling is an option for the fuel management strategy in order to reduce the amount of the spent fuel. The use of the uranium-plutonium mixed oxide fuel (MOX) nowadays is a current practice in several nuclear countries. The use of MOX fuel in reactor core causes a harder neutron spectrum and consequently influences a void reactivity coefficient. Comparing to the uranium oxide fuel, plutonium isotopes have a different neutronic effects, since they decrease the fission-to-capture ratios for actinides at thermal energies of the system $[1,2]$. This paper introduces estimated void reactivity coefficient values in the full burnup interval for innovative assemblies with high enrichment $\mathrm{UO}_{2}$ and MOX fuels since these assemblies are designed to achieve higher fuel discharge burnup than in modern assemblies.

The plutonium utilization could be more effective if the full core would be loaded with MOX fuel. Previous works were performed in order to evaluate this feasibility [35]. These studies showed that it is possible to have a full MOX core by introducing the enhanced moderation in fuel assemblies. The enhanced moderation can be achieved in two ways, first, by replacing fuel pins with water columns in assembly or by altering fuel pin diameter. Such changes in assemblies with MOX fuel increase the moderation-to-fuel ratio, while the safety limits are satisfied. The first approach 
was chosen in current void reactivity coefficient study since the decrease of fuel pin diameter involves more significant changes in assembly design. Two fuel assemblies' designs with extra moderation were analyzed. 8 and 12 fuel rods were replaced by water holes.

The relation between the void effect and the fuel isotopic composition were studied in the past [6]. It was determined in qualitative significances which isotopes contribute to the positive or negative void effects. In this study, the quantitative decomposition analysis was employed in order to interpret void reactivity coefficient discrepancies between different fuel assemblies' designs. For void coefficients values variations over the burnup analysis the reactivity values were decomposed to separate isotopes values. The decomposed void reactivity coefficient values provide useful quantitative insights to describe the overall behaviour of the void reactivity coefficient in detail. Such analysis allows explaining the overall trend of the void reactivity coefficient in changed moderation conditions by few isotopic reaction rates variations.

The remaining information in this paper is organized as follows. Section 2 presents the description of fuel assemblies' designs and the used methodology for decomposition analysis. Section 3 presents the results of void reactivity coefficient analysis for different fuel assemblies' designs. And the paper is completed with the discussion and conclusions in Section 4.

\section{Methodology}

2.1. Code. The neutron transport calculations for BWR fuel assemblies were performed with the TRITON functional module utilizing the ENDF/B-VI based 238 neutron energy group library distributed with SCALE 6.1 code [7]. TRITON module can be used to provide automated, problem dependent cross section processing followed by multigroup transport calculations for one-, two-, and three-dimensional configurations. Additionally, this functional module is used together with the ORIGEN depletion module to predict isotopic concentrations. Thus TRITON module is able to predict the burnup of nuclear materials in configurations that have a strong spatial dependence on the neutron flux and other physics parameters characterizing the system that is relevant for BWR fuel assemblies which have a high heterogeneity [8].

Before the void reactivity study a validation of an applied computer code combined with the methodology was performed for BWR assembly. The achieved neutronic results were compared with the ones presented in the NEA BWRMOX benchmark $[9,10]$. The SCALE code was not applied in current benchmark. 30 benchmark solutions were submitted to benchmark by approximately 20 participants using a different neutron transport code systems.

The infinitive neutron multiplication and power peaking factors (PPF) were estimated by TRITON functional module. The infinitive multiplication factor is the most important neutronic characteristic which describes fuel assembly behaviour over the burnup. Moreover, it is very complicated to predict the power peaking factor precisely since it depends on the rigorous transport analysis. The comparison of the SCALE

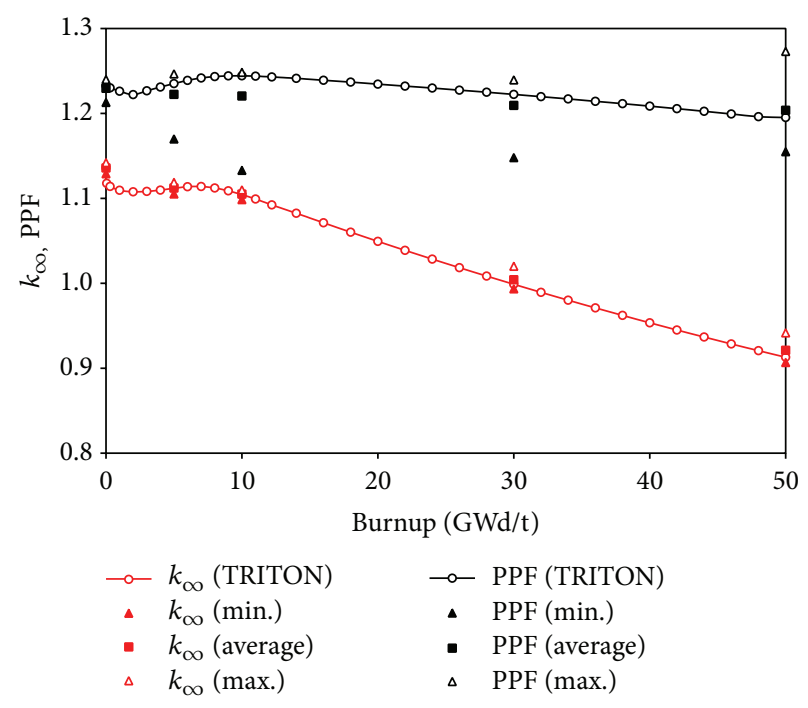

FIGURE 1: Comparison of the SCALE code and benchmark results.

results with the ones of the benchmark participants' results (maximal and minimal values) are depicted in Figure 1. From this figure it can be seen that the results evaluated by TRITON are very close to the average values of the benchmark participants through the full burnup range. Thus it can be stated that the employed code in this study is capable to reflect the processes which take place in BWR fuel assemblies during the irradiation conditions.

2.2. Fuel Assembly Designs. Innovative BWR fuel assembly designs used for void reactivity coefficient analysis are based on the benchmark problem suite for reactor physics study of LWR next generation fuels [11]. This benchmark problem was suggested by working party on Reactors Physics for LWR next generation fuels which was organized in JAERI. It should be noted that the next generation fuel enrichment was increased above existing design limitations for LWR fuels. Next generation LWR fuels discharge burnup target value was set to reach $70 \mathrm{GWd} / \mathrm{t}$.

The lattice configuration of innovative BWR fuel assembly designs with $\mathrm{UO}_{2}$ and MOX fuels is presented in Figure 2. BWR assembly design with uranium oxides fuel consists of $9 \times 9$ geometrical configuration. With an average enrichment of $5.5 \mathrm{wt} \%{ }^{235} \mathrm{U}, \mathrm{UO}_{2}$ assembly contains 74 fuel rods with 5 different fuel compositions, including 16 rods containing $6 \mathrm{wt} \% \mathrm{Gd}_{2} \mathrm{O}_{3}$. This assembly design also contains 2 large water holes which take places of 7 fuel rods. The BWR assembly design with MOX fuel utilizes $10 \times 10$ lattice with an average enrichment of $6.97 \mathrm{wt} \%$ fissile $\mathrm{Pu}$ in which 9 of the fuel rods have been replaced with large water hole. There are 91 fuel rods with 5 different uranium-plutonium and 1 uranium-gadolinium fuel mixtures. The various initial enrichments and locations of the fuels for $\mathrm{UO}_{2}$ and $\mathrm{MOX}$ cases are indicated in Figure 2.

Studies [3-5] showed that it is possible to have the full MOX core with only minor changes on standard fuel assemblies' designs. These changes are related to the enhancing of 

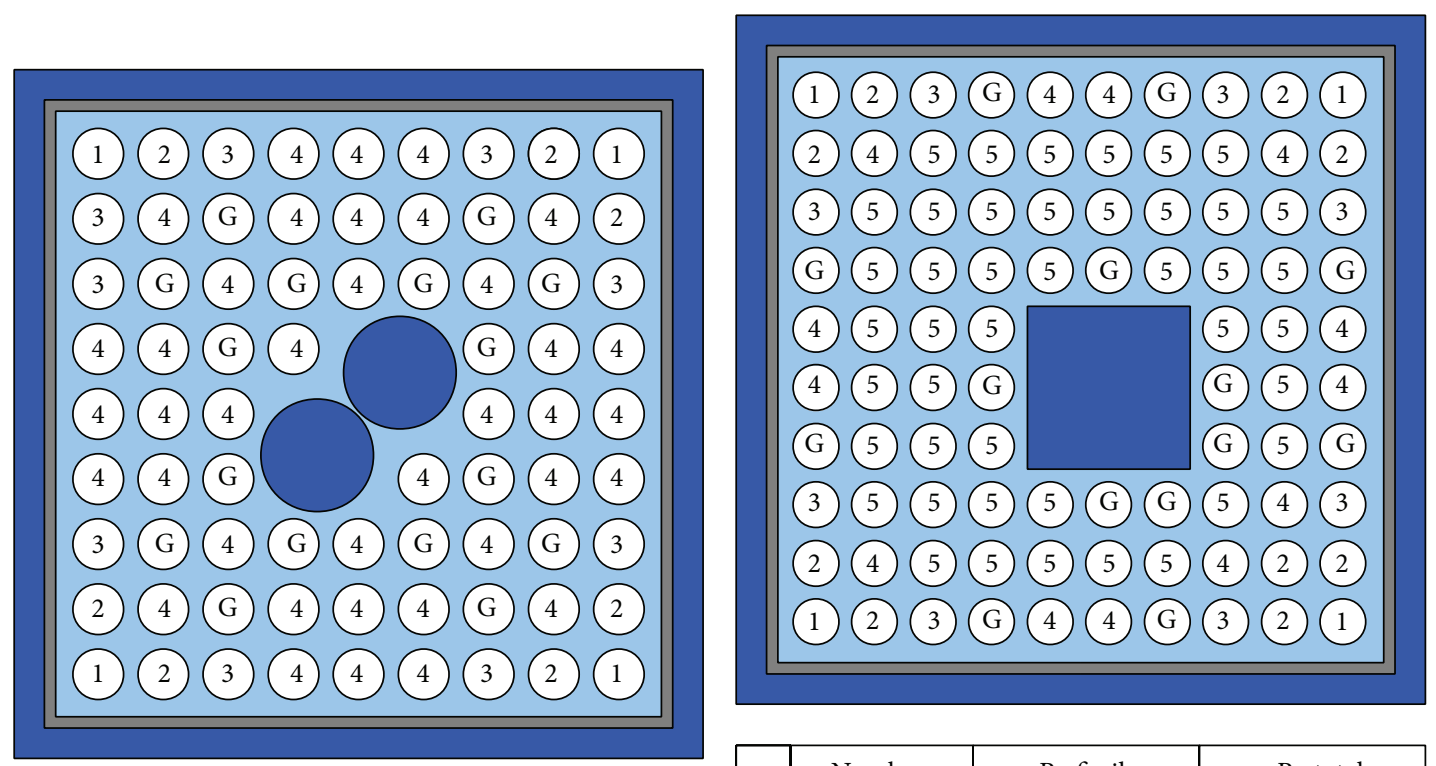

\begin{tabular}{|c|c|c|}
\hline & Number & ${ }^{235} \mathrm{U}$ \\
\hline 1 & 4 & $3 \mathrm{wt} \%$ \\
\hline 2 & 8 & $4 \mathrm{wt} \%$ \\
\hline 3 & 8 & $5 \mathrm{wt} \%$ \\
\hline 4 & 38 & $6.3 \mathrm{wt} \%$ \\
\hline
\end{tabular}

\begin{tabular}{|c|c|c|c|}
\hline & Number & Pu fissile & Pu total \\
\hline 1 & 4 & $2.6 \mathrm{wt} \%$ & $4 \mathrm{wt} \%$ \\
\hline 2 & 9 & $3.8 \mathrm{wt} \%$ & $6 \mathrm{wt} \%$ \\
\hline 3 & 8 & $6.4 \mathrm{wt} \%$ & $10 \mathrm{wt} \%$ \\
\hline 4 & 13 & $7.7 \mathrm{wt} \%$ & $12 \mathrm{wt} \%$ \\
\hline 5 & 43 & $10.2 \mathrm{wt} \%$ & $16 \mathrm{wt} \%$ \\
\hline
\end{tabular}

\begin{tabular}{|l|l|l|l|}
\hline $\mathrm{G}$ & 16 & $\mathrm{Gd}_{2} \mathrm{O}_{3}-6 \mathrm{wt} \%$ & ${ }^{235} \mathrm{U}-5 \mathrm{wt} \%$ \\
\hline
\end{tabular}

(a)

\begin{tabular}{|l|l|l|l|}
\hline $\mathrm{G}$ & 14 & $\mathrm{Gd}_{2} \mathrm{O}_{3}-3.5 \mathrm{wt} \%$ & ${ }^{235} \mathrm{U}-5 \mathrm{wt} \%$ \\
\hline
\end{tabular}

(b)

FIGURE 2: Innovative BWR assemblies designs with $\mathrm{UO}_{2}$ fuel (a) and MOX fuel (b).

moderation in fuel assemblies. The simplest way to increase the moderation to fuel ratio is to use water holes in place of a small fraction of fuel rods per assembly. Taking this into account, the innovative BWR assembly design with MOX fuel was modified in order to enhance the moderation; that is, 8 and 12 fuel rods were replaced by water holes. Modified fuel assemblies' designs are shown in Figure 3. The average enrichment of fissile $\mathrm{Pu}$ for fuel assemblies with 8 and 12 water holes is $6.83 \mathrm{wt} \%$ and $6.56 \mathrm{wt} \%$ accordingly. The specification of BWR fuel assemblies' designs main data, which were applied for decomposition analysis are presented in Table 1.

2.3. Void Reactivity Coefficient Calculation. BWR assembly's structural materials and water temperatures were fixed at $600 \mathrm{~K}$ and fuel temperature was fixed at $900^{\circ} \mathrm{K}$ for the depletion analysis. The power density was assumed as a constant ( $25 \mathrm{~W} / \mathrm{g}$ of heavy metals) during the fuel irradiation time.

BWR assemblies are very heterogeneous since the twophase flow is presented in the reactor core during the operation. There are the bypass regions in BWR assemblies which are separated from the two-phase flow: central water channels, water holes, and gaps between surrounding assemblies. It was assumed a single-phase flow (pure liquid water) for bypass regions, having density equal to $0.737 \mathrm{~g} / \mathrm{cm}^{3}$. Meanwhile the fuel channels outlet voidage could vary, in general, from $0 \%$ to $100 \%$ including severe accidents. The operational data [10] show that the void fraction in average is equal to $40 \%$ for typical BWR core. Based on this fact, the void reactivity coefficients were estimated from two reactor core boundary conditions: in cases of the fuel channel outlet voidage equal to $40 \%$ (water density $0.457 \mathrm{~g} / \mathrm{cm}^{3}$ ) and $100 \%$ (water density $0.037 \mathrm{~g} / \mathrm{cm}^{3}$ ). The difference of the reactivity between these two boundary conditions reflects the void reactivity effect in case of the transient from normal operation conditions to the loss of coolant accident. The void reactivity coefficient is defined as a ratio:

$$
\alpha(v)=\frac{\Delta \rho_{\text {inf }}}{\Delta v} .
$$

The analysis of decomposing into separate isotopes was performed to explain the void reactivity coefficient variations during the fuel irradiation process and to outline specifics for 

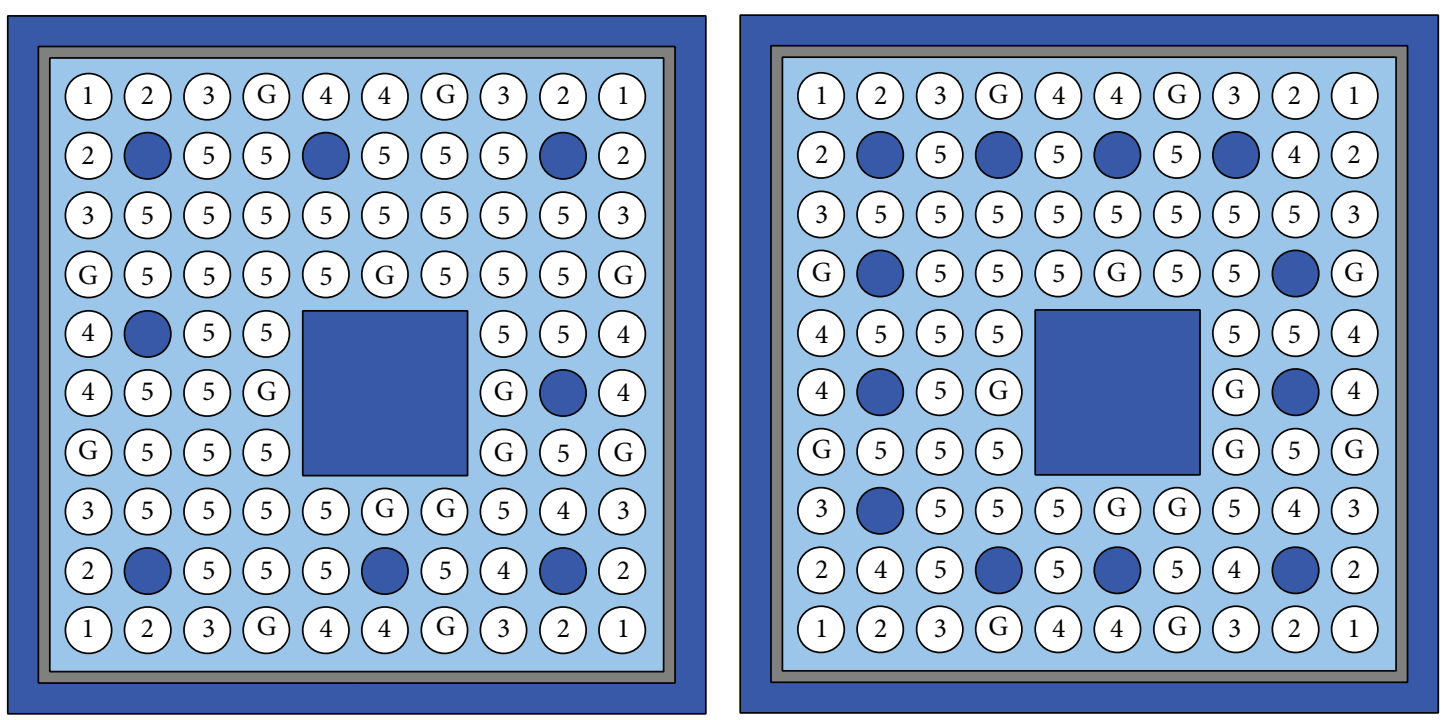

\begin{tabular}{|c|c|c|c|}
\hline & Number & Pu fissile & Pu total \\
\hline 1 & 4 & $2.6 \mathrm{wt} \%$ & $4 \mathrm{wt} \%$ \\
\hline 2 & 8 & $3.8 \mathrm{wt} \%$ & $6 \mathrm{wt} \%$ \\
\hline 3 & 8 & $6.4 \mathrm{wt} \%$ & $10 \mathrm{wt} \%$ \\
\hline 4 & 10 & $7.7 \mathrm{wt} \%$ & $12 \mathrm{wt} \%$ \\
\hline 5 & 39 & $10.2 \mathrm{wt} \%$ & $16 \mathrm{wt} \%$ \\
\hline
\end{tabular}

\begin{tabular}{|c|c|c|c|}
\hline & Number & Pu fissile & Pu total \\
\hline 1 & 4 & $2.6 \mathrm{wt} \%$ & $4 \mathrm{wt} \%$ \\
\hline 2 & 8 & $3.8 \mathrm{wt} \%$ & $6 \mathrm{wt} \%$ \\
\hline 3 & 8 & $6.4 \mathrm{wt} \%$ & $10 \mathrm{wt} \%$ \\
\hline 4 & 12 & $7.7 \mathrm{wt} \%$ & $12 \mathrm{wt} \%$ \\
\hline 5 & 33 & $10.2 \mathrm{wt} \%$ & $16 \mathrm{wt} \%$ \\
\hline
\end{tabular}

\begin{tabular}{|c|c|c|c|}
\hline $\mathrm{G}$ & 14 & $\mathrm{Gd}_{2} \mathrm{O}_{3}-3.5 \mathrm{wt} \%$ & ${ }^{235} \mathrm{U}-5 \mathrm{wt} \%$ \\
\hline
\end{tabular}

(a)

\begin{tabular}{|l|l|l|l|}
\hline $\mathrm{G}$ & 14 & $\mathrm{Gd}_{2} \mathrm{O}_{3}-3.5 \mathrm{wt} \%$ & ${ }^{235} \mathrm{U}-5 \mathrm{wt} \%$ \\
\hline
\end{tabular}

(b)

FIgURE 3: Modified BWR assemblies designs with 8 (a) and 12 (b) water holes.

TABLE 1: Innovative BWR fuel assemblies's specifications.

\begin{tabular}{lcccc}
\hline Fuel assembly design & $\mathrm{UO}_{2}$ & MOX & MOX + 8 holes & MOX + 12 holes \\
\hline Discharge burnup (GWd/t) & & & 70 & $10 \times 10$ \\
Geometrical configuration & $9 \times 9$ & 91 & 63 & 79 \\
Number of fuel rods & 74 & 6.97 & 14 & \\
Average enrichment (wt\%) & 5.50 & & 15.24 & 1.295 \\
Number of U-Gd rods & 16 & & 2.18 \\
Assembly pitch (cm) & 1.440 & 1.90 & & 2.35 \\
Fuel rod pitch (cm) & 1.89 & & & \\
Moderator-to-fuel ratio & & & & \\
\hline
\end{tabular}

different fuel assemblies' designs. For this purpose the total void reactivity coefficient value was decomposed into separate components which represent contribution of individual isotope on neutrons absorption reactions.

The neutron multiplication factor $k_{\text {inf }}$ and the reactivity $\rho_{\text {inf }}$ can be expressed by decomposing them to their isotopic dependence as following:

$$
k_{\mathrm{inf}}=\frac{\sum P_{i}}{\sum A_{i}}, \quad \rho_{\mathrm{inf}}=\frac{\sum P_{i}-\sum A_{i}}{\sum P_{i}} .
$$

Index $i$ flags isotopes in the system, $P$ : neutrons production rate and $A$ : neutrons absorption rate. In the following, we consider the voidage dependent isotopic reaction rates as normalized to a total neutron production of unity. Finally, the void reactivity coefficient can be expressed as follows:

$$
\alpha(v)=\frac{d \rho_{\mathrm{inf}}}{d v}=\frac{d \sum\left(-A_{i} / \sum P_{i}\right)}{d v} .
$$




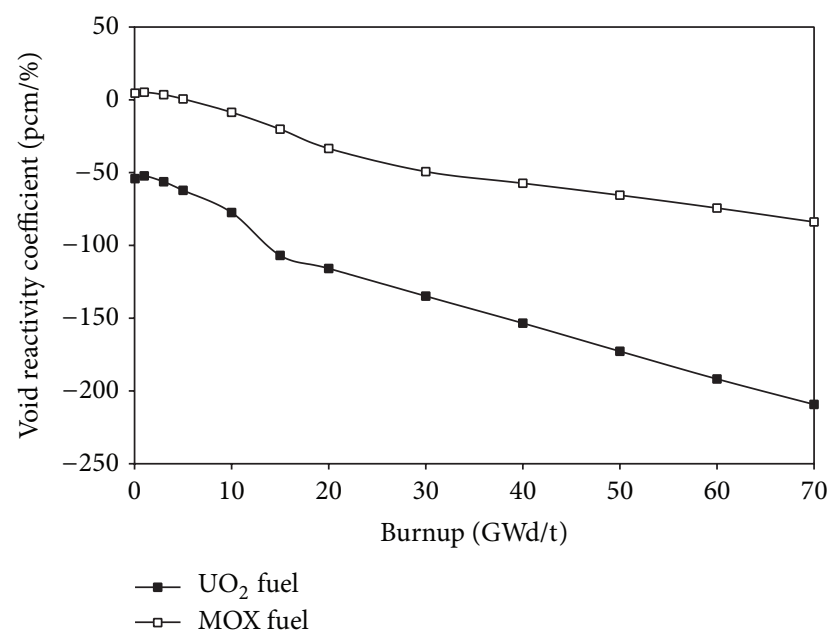

FIGURE 4: Void reactivity coefficient varying during burnup for innovative assemblies' designs.

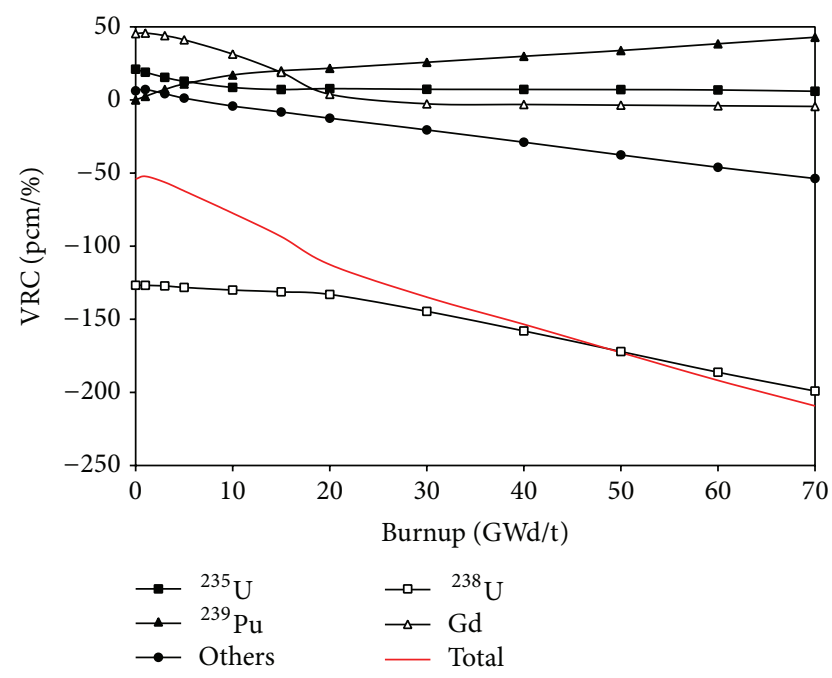

FIGURE 5: Decomposition of VRC values for separate isotopes in case of $\mathrm{UO}_{2}$.

The TRITON module can output fractional absorptions data for individual isotopes. Accordingly the void coefficient value, applying these data, can be expressed as follows:

$$
\alpha(v)=\frac{d \rho_{\mathrm{inf}}}{d v}=\frac{d \sum\left(-a_{i} / k_{\mathrm{inf}}\right)}{d v} .
$$

Here $\alpha_{i}$ is fractional neutrons absorption for isotope $i$. Final expression of void reactivity coefficient would be

$$
\alpha(v)=\sum_{i} \frac{a_{i, v 100} \cdot k_{\mathrm{inf}, v 0}-a_{i, v 0} \cdot k_{\mathrm{inf}, v 100}}{\Delta v \cdot k_{\mathrm{inf}, v 0} \cdot k_{\mathrm{inf}, v 100}} .
$$

Indexes $v 40$ and $v 100$ stand for different voiding conditions in fuel assemblies.

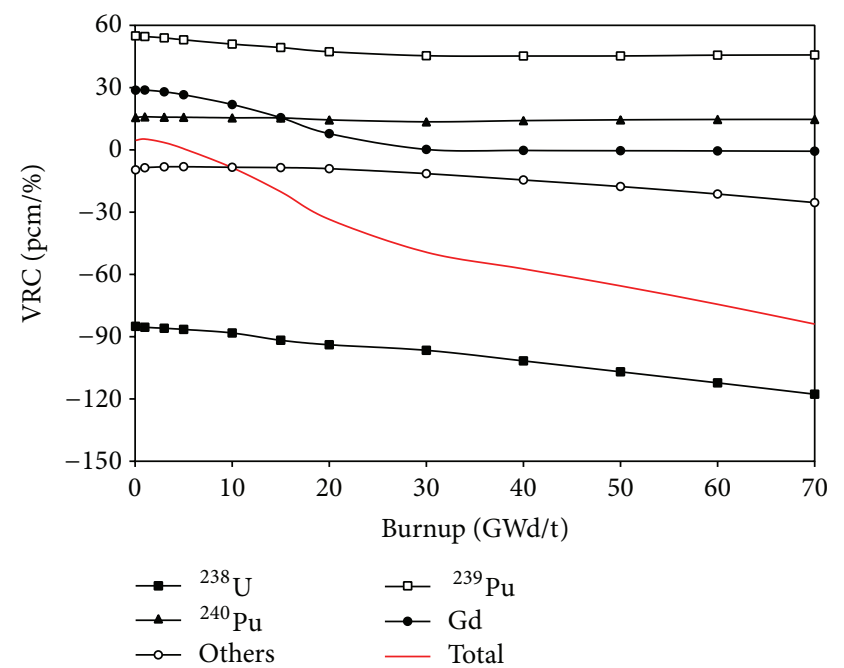

FIGURE 6: Decomposition of VRC values for separate isotopes in MOX.

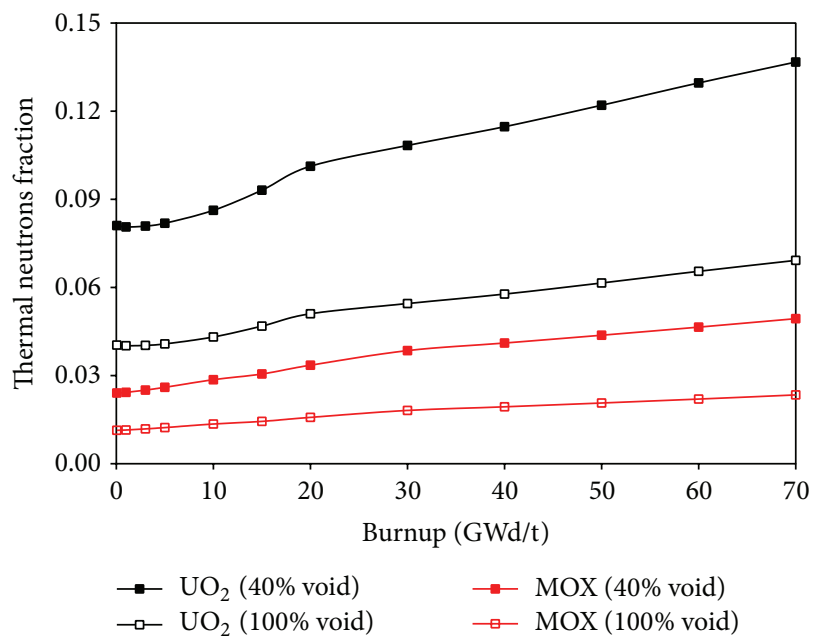

FIGURE 7: Thermal neutrons fractions for innovative assemblies' designs.

\section{Results}

3.1. Void Reactivity Coefficient for Innovative Assemblies' Designs. The observed differences of void reactivity effects for innovative assemblies' designs loaded with $\mathrm{UO}_{2}$ and MOX fuels are presented in this section. The void reactivity coefficients over the fuel burnup which evaluates reactivity changes when void fraction increases from $40 \%$ to $100 \%$ are depicted in Figure 4. It can be seen that void reactivity coefficients have strong dependency on the fuel burnup and negative coefficients values for assembly design with $\mathrm{UO}_{2}$ fuel are larger (50-120 $\mathrm{pcm} / \%)$ comparing to MOX fuel. Thus differences of void reactivity effects between $\mathrm{UO}_{2}$ fuel and MOX fuel have to be considered during loading the core with MOX fuel since it would lead to significant differences of the reactivity alterations between fuel assemblies during void fraction changes. There are positive coefficients values 


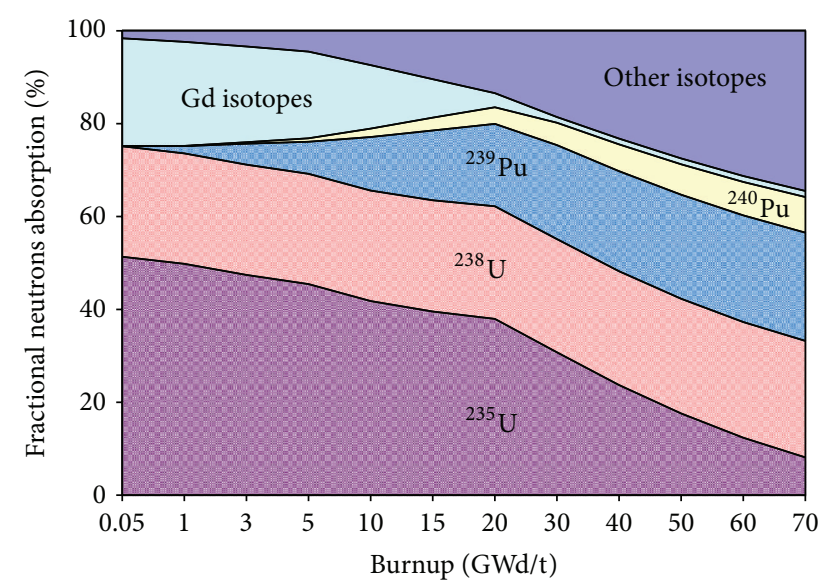

FIgURE 8: Fractional neutrons absorption in $\mathrm{UO}_{2}$ fuel.

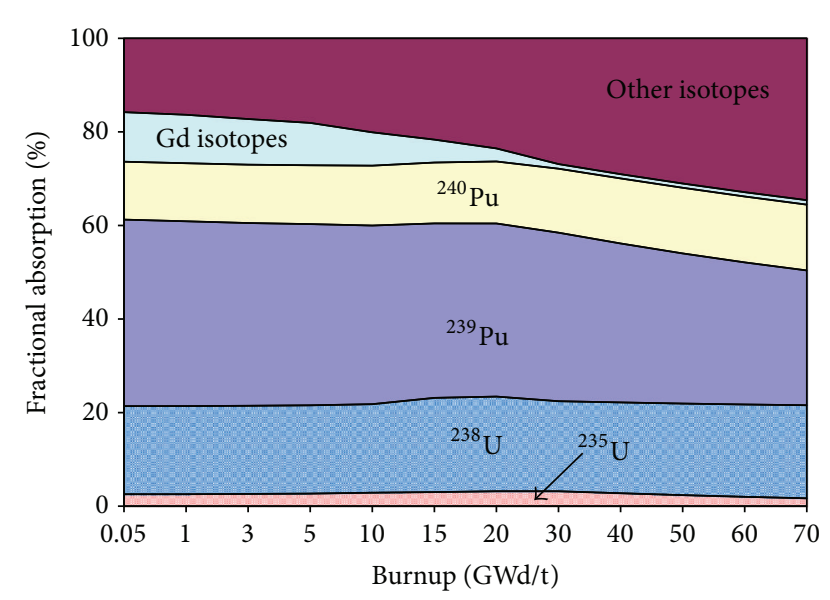

FIgURE 9: Fractional neutrons absorption in MOX fuel.

for assembly design with MOX fuel at the beginning of the fuel irradiation, which means that there is a reactivity increase in case of void formation in assembly with MOX fuel.

The decomposition of void reactivity coefficient values into separate isotopes values for innovative BWR assemblies with $\mathrm{UO}_{2}$ and MOX fuels is shown in Figures 5 and 6. These figures represent main isotopes which have the substantial impact to void reactivity coefficient values for corresponded assemblies' designs. Gd curves represent the sum of all Gd isotopes included in fuel depletion calculation: ${ }^{152} \mathrm{Gd},{ }^{154} \mathrm{Gd}$, ${ }^{155} \mathrm{Gd},{ }^{156} \mathrm{Gd},{ }^{158} \mathrm{Gd}$, and ${ }^{160} \mathrm{Gd}$. Curves named as "others" are equivalent to the sum of coefficient values of remaining isotopes.

As it can be seen from Figures 5 and 6 , the ${ }^{238} \mathrm{U}$ isotope has the largest weight to negative void reactivity coefficients values. ${ }^{238} \mathrm{U}$ isotope produces negative coefficient values since one-group neutrons absorption rates increase during void fraction increase. Coefficient values of Gd and fissile isotopes $\left({ }^{235} \mathrm{U},{ }^{239} \mathrm{Pu}\right.$, and $\left.{ }^{241} \mathrm{Pu}\right)$ remain positive despite of the decrease of neutron absorption reaction rates of the mentioned isotopes. Many plutonium isotopes have larger

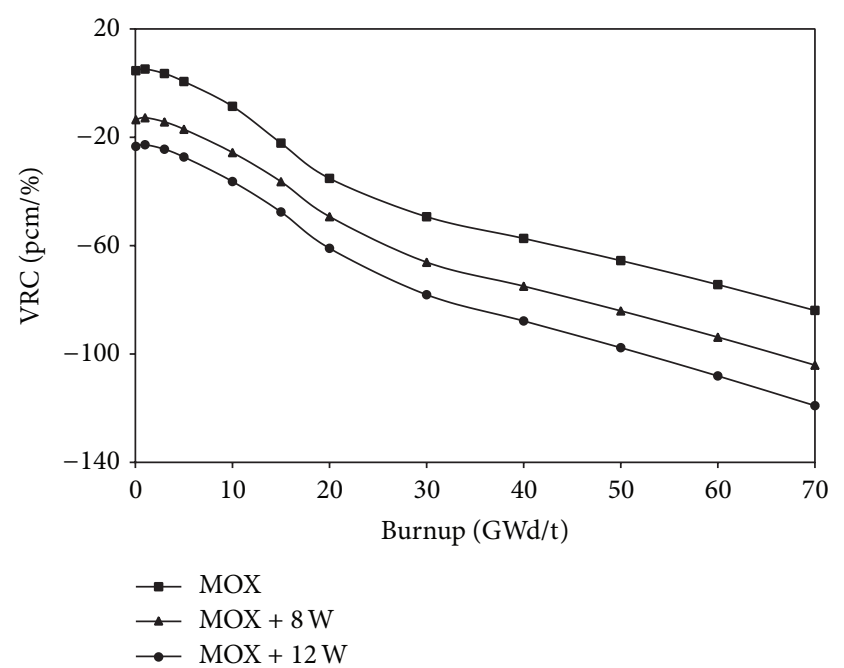

FIGURE 10: Void reactivity coefficients varying during burnup for modified assemblies' designs.

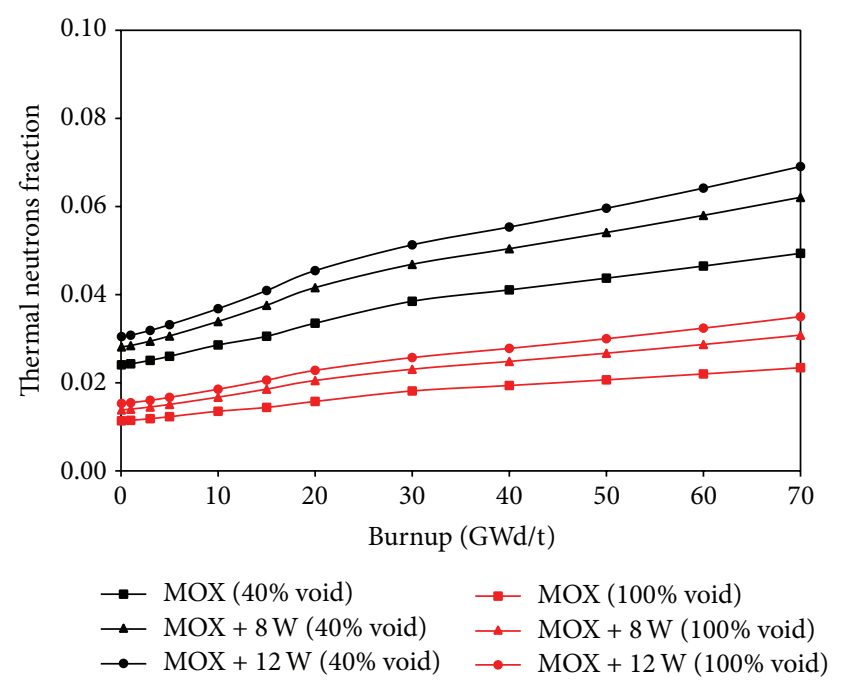

FIGURE 11: Thermal neutrons fractions for modified assemblies' designs.

absorption cross sections than uranium ones; thus the onegroup cross section of the plutonium fuel is larger than the one for uranium. The presence of the plutonium large onegroup absorption cross section in MOX fuel causes a reduced thermal flux, which can be seen in Figure 7. Also, Figure 7 presents the ratio of the thermal neutron flux against the total neutron flux for different void states and for both fuel types. It can be seen from the same figure that the reduced neutron moderation due to the void formation causes the neutron flux hardening.

Void coefficient values' variation over the fuel depletion for ${ }^{238} \mathrm{U}$ isotope depends on the neutron spectrum changes since the concentration of ${ }^{238} \mathrm{U}$ nuclides decreases marginally (reduces by $5 \%$ ). The changes in the fuel composition during 


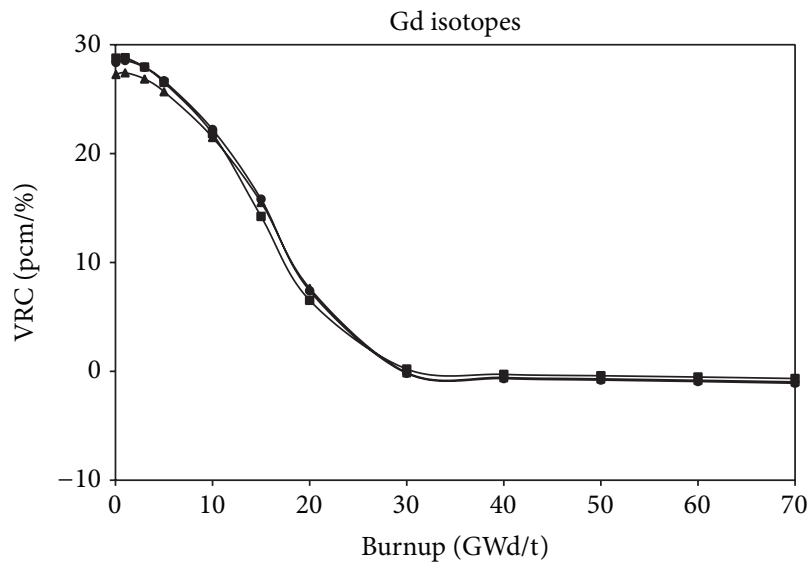

(a)

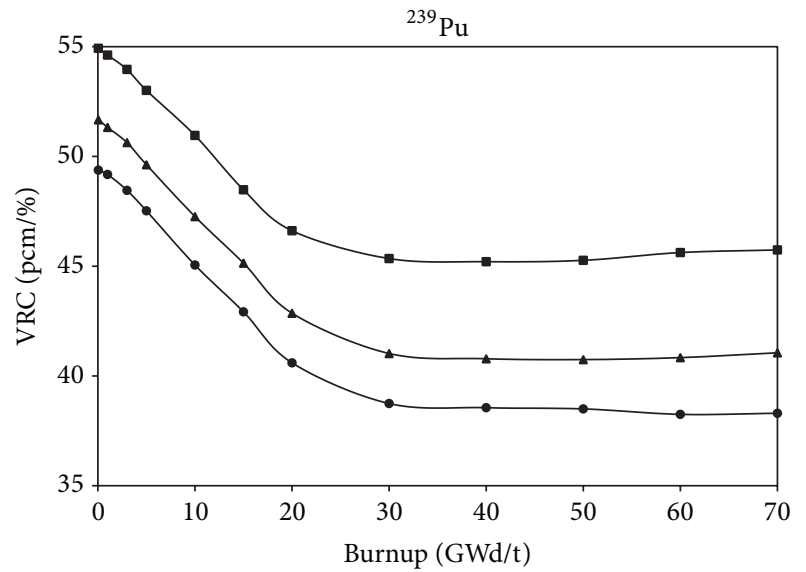

(c)

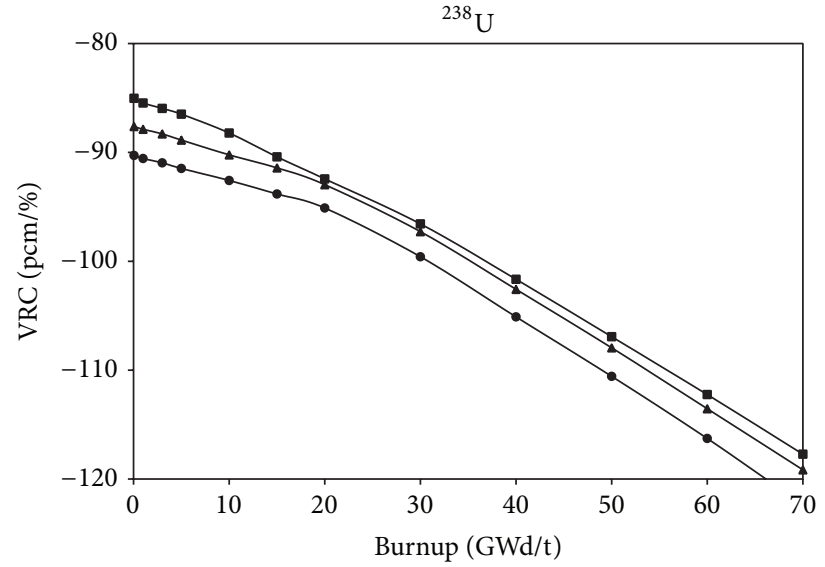

(b)

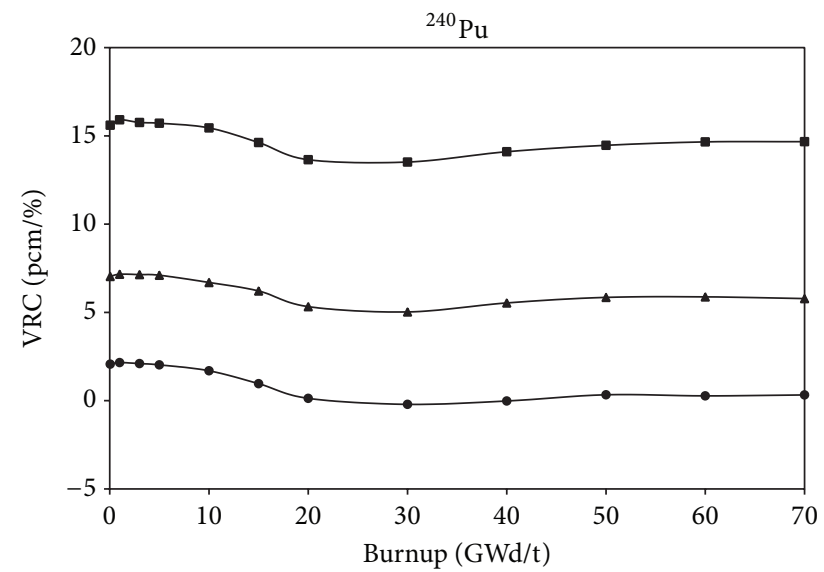

(d)

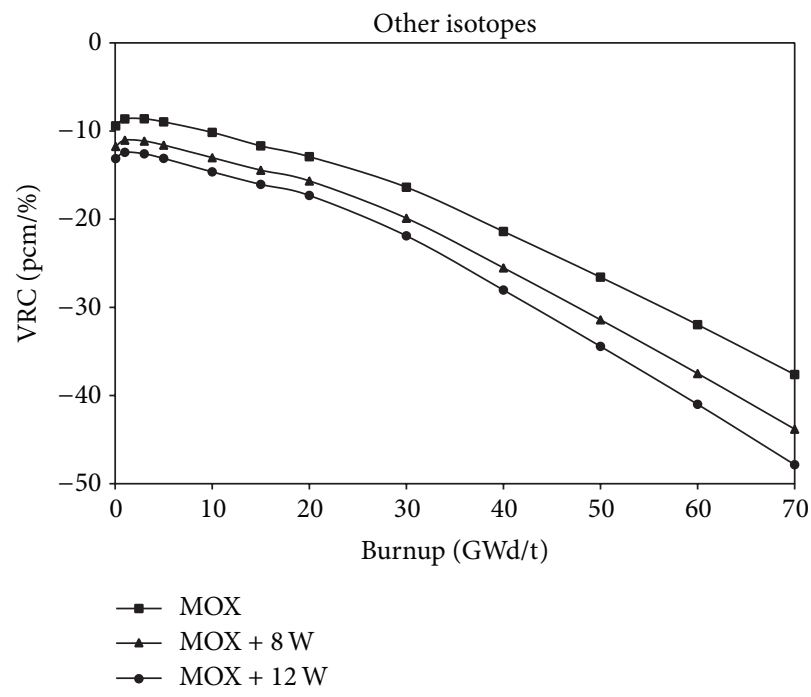

(e)

FiguRE 12: Void reactivity coefficients values for separate isotopes in modified assemblies' designs. 
the fuel burnup cause the flux changes and subsequently absorption characteristic changes. During the fuel depletion, the number of fissile isotopes decreases, which cause the increase of thermal neutron fraction. The ${ }^{238} \mathrm{U}$ absorption cross section becomes more dominant for system with higher thermal neutron fraction and less fissile material, while neutron spectrum becomes much harder during voiding (Figures 5 and 6).

The fractional neutron absorption for $\mathrm{UO}_{2}$ and MOX fuel is presented in Figures 8 and 9. Changes of isotopes absorption over the fuel irradiation are strongly related to changes of isotopes concentration. As it was shown in Figures 5 and $6 \mathrm{Gd}$ isotopes have high positive coefficient values at the beginning of the fuel irradiation with the presence of ${ }^{155} \mathrm{Gd}$ and ${ }^{157} \mathrm{Gd}$ isotopes which have a high thermal neutron absorption rates. As fuel achieves $20 \mathrm{GWd} / \mathrm{t}$ burnup level, the effect of Gd becomes slightly negative due to the burnout of nuclides.

The impact of ${ }^{239} \mathrm{Pu}$ and ${ }^{240} \mathrm{Pu}$ isotopes is high for MOX fuel in comparison to uranium fuel. It can be seen from Figures 8 and 9 that the fractional absorption of ${ }^{239} \mathrm{Pu}$ is greater in MOX fuel, while ${ }^{239} \mathrm{Pu}$ becomes significant factor for uranium fuel after fuel burnup over $20 \mathrm{GWd} / \mathrm{t}$. Thus the positive void effect created by ${ }^{239} \mathrm{Pu}$ is larger for MOX fuel and it is related to the decrease of thermal neutrons absorptions in case of the reduced neutrons moderation. ${ }^{240} \mathrm{Pu}$ gives higher coefficient values for MOX fuel since ${ }^{240} \mathrm{Pu}$ absorbs relatively much more neutrons in MOX fuel (13-15\%). ${ }^{240} \mathrm{Pu}$ contributes to positive void effect since absorptions of thermal and fast neutrons decrease during the void formation.

\subsection{Void Reactivity Coefficient for Modified Assemblies'} Designs. There are concerns associated with the use of MOX fuel in comparison with the uranium fuel usage. Firstly, it is a harder neutron spectrum leading to a shorter neutron lifetime and secondly a lower delayed neutron fraction, which could allow the reactor to go prompt to critical state faster. As it was shown in Figure 4, the positive void reactivity coefficient values at the beginning of fuel irradiation is observed for MOX fuel. The implementing of additional water holes in place of fuel rods enhanced neutrons moderation and the neutron spectrum became softer (Figure 11). The comparison of void reactivity coefficient in innovative fuel assembly design loaded with MOX fuel (results of previous section) and modified by water holes assemblies' designs is depicted in Figure 10. One can see that the void coefficient is lower for enhanced neutron moderation cases through a whole burnup interval.

The impact of the main isotopes to the behaviour of the void coefficient during the fuel burnup is presented in Figure 12. The character of the influence is the same for both assembly designs, that is, with MOX fuel and water holes. The positive impact of ${ }^{239} \mathrm{Pu}$ and ${ }^{240} \mathrm{Pu}$ to the void effect with enhanced moderation decreases by -7 and $-14 \mathrm{pcm} / \%$, respectively. Meanwhile, the absolute values of void coefficient for ${ }^{238} \mathrm{U}$ and "other" increase by -5 and $-10 \mathrm{pcm} / \%$ with the same enhanced moderation.

\section{Discussion and Conclusions}

A detailed void reactivity coefficient study was performed for innovative assemblies' designs loaded with the high enrichment $\left(>5 \%{ }^{235} \mathrm{U}\right)$ uranium fuel and the corresponding enrichment of MOX fuel. Additionally, two modified assembly designs with MOX fuel were analyzed as well. The decomposition of void reactivity coefficient, analyzing the influence of separate isotopes, showed that fissile materials $\left({ }^{235} \mathrm{U}\right.$, ${ }^{239} \mathrm{Pu}$, and ${ }^{241} \mathrm{Pu}$ ) and isotopes of the burnable absorber Gd contribute to the positive void effect in both uranium and MOX fuels. Thus the increase of the fissile material enrichment in the fuel would result in higher values of the void reactivity coefficient. Higher concentration of Gd isotopes would contribute to higher coefficient values at the beginning of the fuel irradiation as well.

Negative void reactivity coefficient values are mainly determined by the fast neutrons capture in ${ }^{238} \mathrm{U}$ nuclides. The negative void effect by ${ }^{238} \mathrm{U}$ is presented since the fast neutrons capture is increasing during the void formation. The study showed that such acceleration of fast neutrons captures is proportional to the neutrons spectrum; that is, the increase is smaller for harder neutrons spectrum.

The change in void fraction during the transient would affect larger void effects in case of the uranium fuel comparing to the MOX fuel case. For safety reasons, it is important to consider that the increase/decrease of flow rates is an important measure for reactor power and reactivity control in BWR reactors. Changes in the reactivity for assembly design with MOX fuel due flow rates alterations would be not so significant as in case of assembly design with uranium fuel.

Another important safety concern is a positive void reactivity coefficient values for assembly with MOX fuel at the beginning of the fuel irradiation (up to $5 \mathrm{GWd} / \mathrm{t}$ ). Thus the operation of assemblies with MOX fuel is acceptable in only case when a part of reactor core is loaded with such assemblies (as in nowadays practice).

The analysis of innovative assemblies with the enhanced moderation and MOX fuel showed that void coefficient values are decreasing with increase of the moderation to the fuel ratio. The results of the decomposition analysis showed that the enhanced moderation has contributed to the softer neutron spectrum and influenced the decrease of the void coefficient for separate isotopes. Based on the analysis results it can be stated that such modified assemblies can be employed in the homogeneous core without encountering a positive void effect.

Moreover, with reference to the results of this study and experience gained, the decomposition analysis appeared to be an extremely useful instrument and can provide quantitative insights for neutronic characteristics analysis.

\section{Conflict of Interests}

The authors declare that there is no conflict of interests regarding the publication of this paper. 


\section{References}

[1] H. R. Trellue, "Safety and neutronics: a comparison of MOX versus $\mathrm{UO}_{2}$ fuel," Progress in Nuclear Energy, vol. 48, no. 2, pp. 135-145, 2006.

[2] R. Ramirez-Sanchez, R. T. Perry, V. Gustavo Alonso, and H. Javier Palacios, "MOX fuel assembly design equivalent to enriched uranium fuel for BWR," in Proceedings of the International Conference on the Physics of Reactors "Nuclear Power: A Sustainable Resource” (PHYSOR '08), pp. 1528-1532, CasinoKursaal Conference Center, Interlaken, Switzerland, September 2008.

[3] J. L. François, C. M. D. Campo, and J. Hernández, "Design of an overmoderated fuel and a full MOX core for plutonium consumption in boiling water reactors," Annals of Nuclear Energy, vol. 29, no. 16, pp. 1953-1965, 2002.

[4] T. Yamamoto, T. Umano, R. Kanda et al., "Core physics experiments and their analysis of high moderation full MOX BWR," in Proceedings of the International Conference on Global Environment and Advanced Nuclear Power Plants (GENES4/ANS '03), Paper 1123, Kyoto, Japan, September 2003.

[5] F. Franceschini and B. Petrović, "Core physics analysis of $100 \%$ MOX core in IRIS," Annals of Nuclear Energy, vol. 35, no. 9, pp. 1587-1597, 2008.

[6] Z. Jitka and J. Wallenius, "Void reactivity feedback in BWRs with MA bearing MOX fuels," Annals of Nuclear Energy, vol. 38, no. 9, pp. 1968-1977, 2011.

[7] "A Comprehensive Modeling and Simulation Suite for Nuclear Safety Analysis and Design," ORNL/TM-2005/39, Version 6.1, June 2011.

[8] M. D. DeHart, "Lattice physics capabilities of the SCALE code system using TRITON," in Proceedings of the International Conference on the Physics of Reactors, Vancouver, British Columbia, Canada, September 2006.

[9] M. Pecchia, G. Kotev, C. Parisi, and F. D’Auria, "MOx benchmark calculations by deterministic and Monte Carlo codes," Nuclear Engineering and Design, vol. 246, pp. 63-68, 2012.

[10] J. L. Francois and C. Martin del Campo, "Lattice physics codes comparisons for the NEA BWR-MOX benchmark," in Proceedings of the International Topical Meeting on Advances in Reactor Physics and Mathematics and Computation into the Next Millennium, Pittsburgh, Pa, USA, May 2000.

[11] A. Yamamoto, T. Ikehara, I. T. O. Takuya, and E. Saji, "Benchmark problem suite for reactor physics study of LWR next generation fuels," Journal of Nuclear Science and Technology, vol. 39, no. 8, pp. 900-912, 2002. 


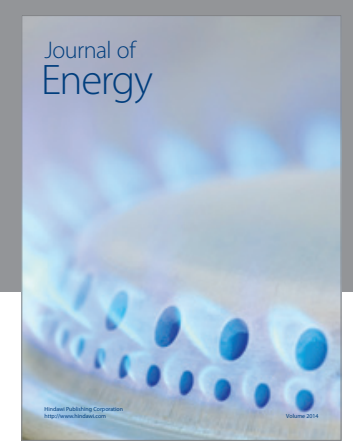

Journal of

Industrial Engineering
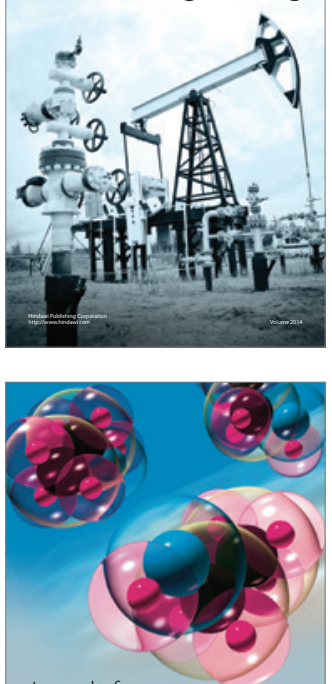

Fuels
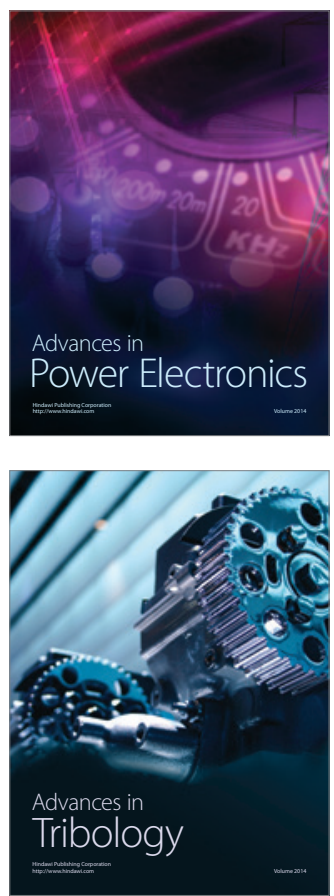

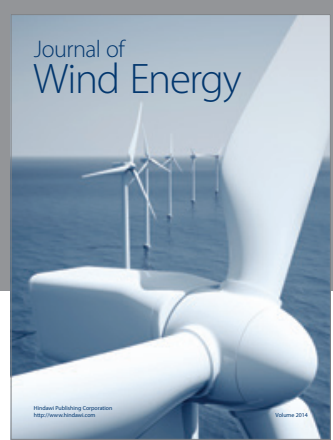

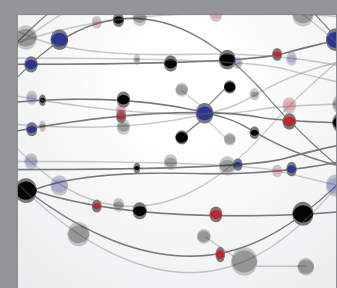

The Scientific World Journal

Submit your manuscripts at http://www.hindawi.com

Journal of

Structures
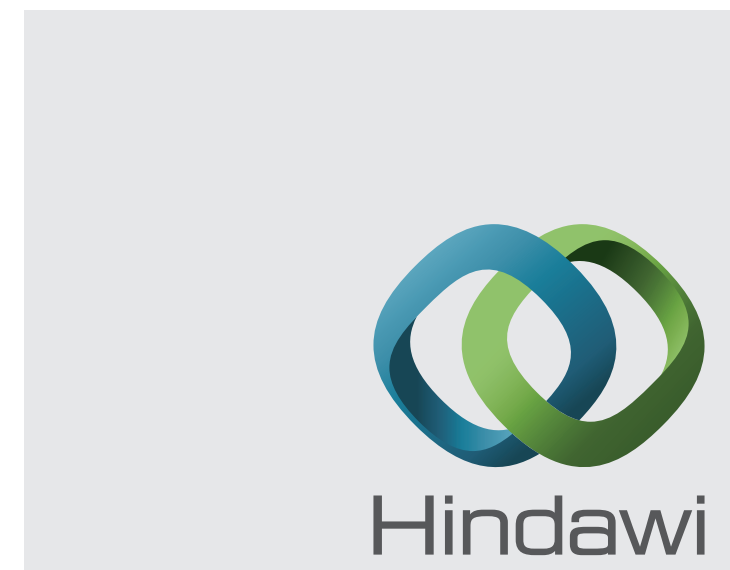

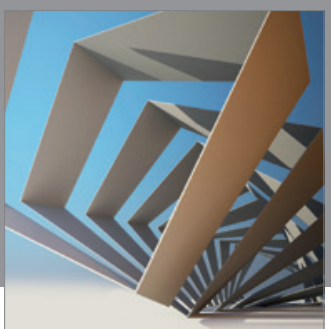

Rotating

Machinery
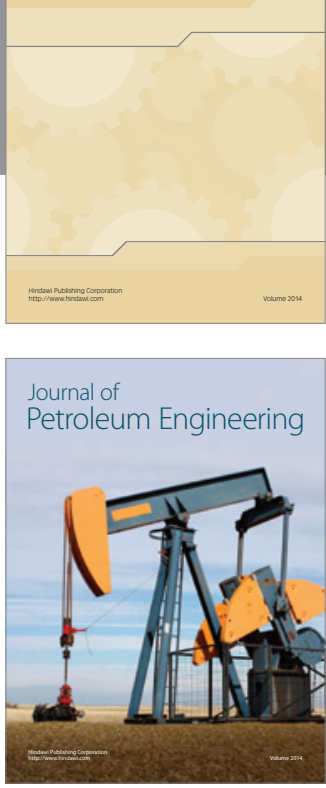

Journal of

Solar Energy
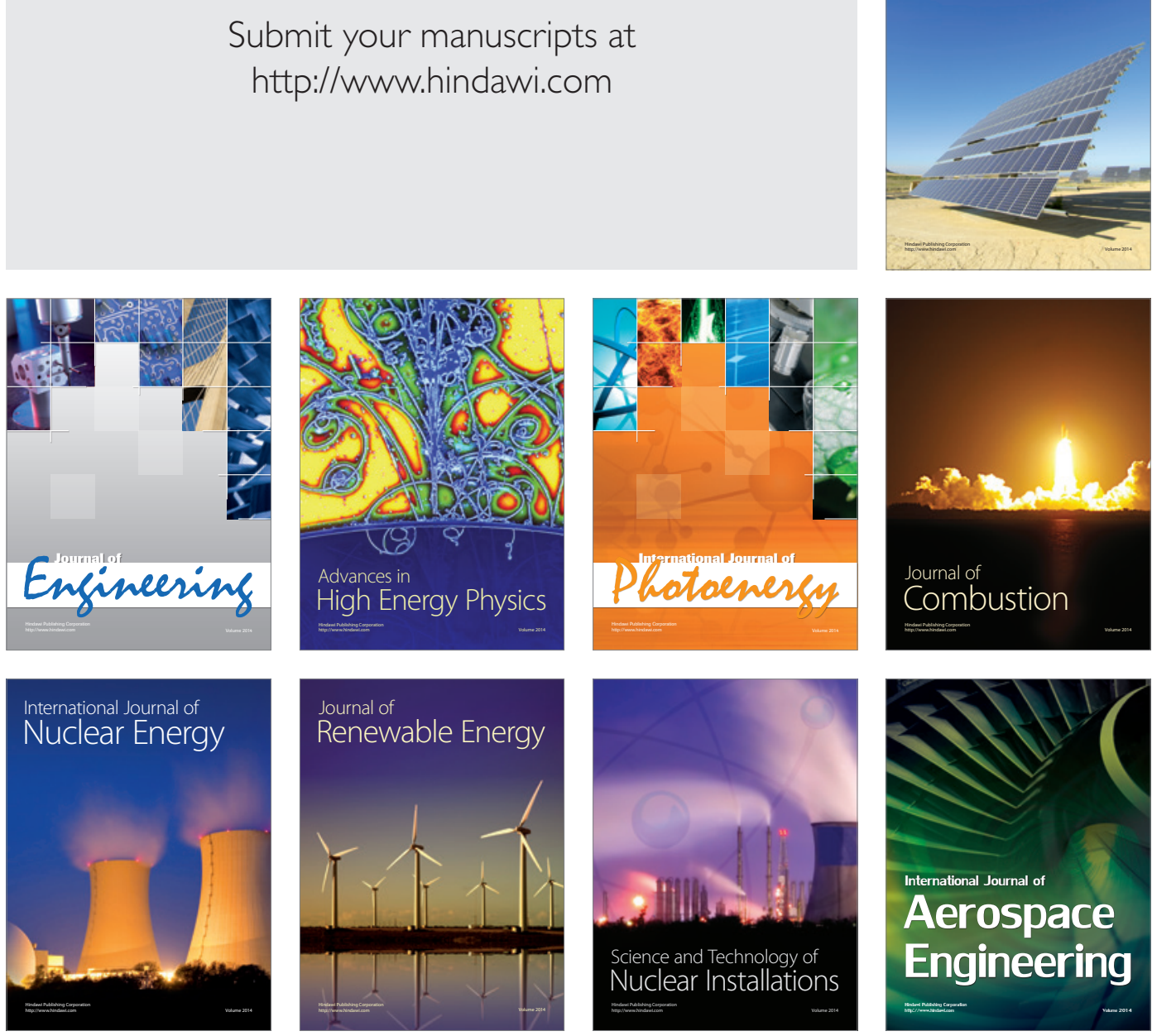